\title{
Managing purchasing with different e-procurement solutions
}

\begin{abstract}
Increased demand from the market to carry out rapid business transactions has led many companies to seek to improve their regular business transactions. The progressive development of the internet in establishing a variety of electronic marketplaces has facilitated companies to move towards applying e-procurement technologies. This indirectly increases the competitiveness of companies due to well managed purchasing activities using eprocurement technologies. The strategic decision by the top management in implementing eprocurement technologies is mainly concentrated on managing the supply of external resources and preferred to focus on the implementation of green supply chain activities to increase the environmental performance with e-procurement technologies. With the spread of internet technologies, which led to changes in business strategy and its uses, companies will be provided with a digital platform for online business transactions. Therefore, business through electronic media (e-media) have the potential and power to transform business transactions and business relationships. E-procurement became the most important strategy for the business to purchase or procure goods or materials from global suppliers. Despite the claims on usability of e-procurement technologies, some companies however show little interest in applying e-procurement technologies because of the difficulty the companies to perform purchasing activities and other key aspects that influence the companies to exploit the technologies. As a major contributor to the growth of the agriculture sector, the Malaysia Palm Oil Industry (MPOI) should explore the potential of e-procurement and other relevant technologies to be exploited in the industry and enhance its competitiveness. The information on the applicability of e-procurement technologies for different types of materials at different stages of the industry supply chain will assist the industry players to achieve efficient purchasing activities. Hence, in this chapter the case study discussed will provide relevant eprocurement solutions with respect to the MPOI and will provide comprehensive purchasing activities of different types of products along the supply chain through e-procurement technologies.
\end{abstract}

